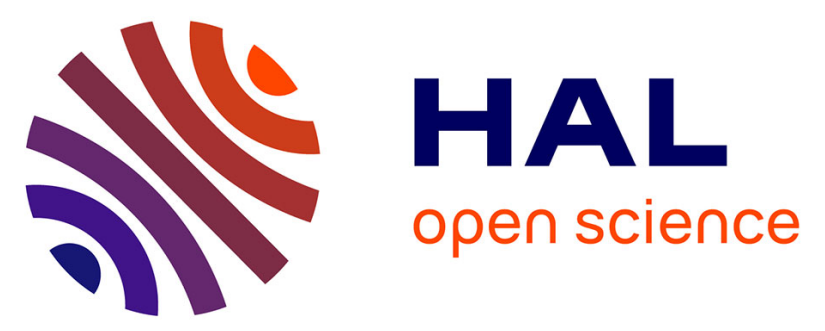

\title{
Study on Laos-China Cross-Border Regional Economic Cooperation Based on Symbiosis Theory: A Case of Construction of Laos Savan Water Economic Zone
} Sisavath Thiravong, Jingrong Xu, Qin Jing

\section{- To cite this version:}

Sisavath Thiravong, Jingrong Xu, Qin Jing. Study on Laos-China Cross-Border Regional Economic Cooperation Based on Symbiosis Theory: A Case of Construction of Laos Savan Water Economic Zone. 9th International Conference on Computer and Computing Technologies in Agriculture (CCTA), Sep 2015, Beijing, China. pp.479-486, 10.1007/978-3-319-48354-2_48 . hal-01614197

\author{
HAL Id: hal-01614197 \\ https://hal.inria.fr/hal-01614197
}

Submitted on 10 Oct 2017

HAL is a multi-disciplinary open access archive for the deposit and dissemination of scientific research documents, whether they are published or not. The documents may come from teaching and research institutions in France or abroad, or from public or private research centers.
L'archive ouverte pluridisciplinaire HAL, est destinée au dépôt et à la diffusion de documents scientifiques de niveau recherche, publiés ou non, émanant des établissements d'enseignement et de recherche français ou étrangers, des laboratoires publics ou privés.

\section{(c)(1)}

Distributed under a Creative Commons Attribution| 4.0 International License 


\title{
Study on Laos-China Cross-boder Regional Economic Cooperation Based on Symbiosis Theory: A Case of Construction of Laos Savan Water Economic Zone
}

\author{
Sisavath THIRAVONG ${ }^{123}$, Jingrong $\mathrm{Xu}^{12^{*}}$, Qin $\mathrm{Jing}^{4}$ \\ 1. Business School of Hohai University, Nanjing, 211100, China; \\ 2. Jiangsu Provincial Collaborative Innovation Center of World Water Valley and Water Ecological \\ Civilization, Nanjing,211100,China; \\ 3. National Electrical Company of Laos \\ 4. China Institute of Water Resources and Hydropower Research,Beijing,100044,China
}

\begin{abstract}
The strategy of "one belt one road" has provided an opportunity of accelerate economic growth for China's surrounding countries. Laos is actively joining the initiative, but how to cooperate with China is a difficulty. Biological symbiosis shares similar characters with cooperation and mutual benefits among cross-border countries. So taking the construction of Savan-Seno Special Economic Zone of Laos as example,we introduced the symbiosis theory and analyzing symbiosis units, models and interfaces between Laos-China regional economic cooperation, it led to the generation, optimization and mechanism under which the symbiotic system was determined. Then we should improve the Laos-China regional economic cooperation symbiosis system by training and harvesting favorable environments, expanding symbiotic interface so as to accelerate the cooperative relationship.
\end{abstract}

Key Words: Qne belt One road; Laos-China; Symbiotic Theory; Cross-boder Regional Economic Cooperation

\section{Introduction}

Chinese President Xi Jinping has put forward the strategic proposal of "Build Silk road economic belt and maritime silk road in the $21^{\text {st }}$ century based on the innovation cooperation mode" in the year of 2013, which has attracted worldwide attention and positive response. That strategy has became the broad consensus and guide of actual action for the countries in Southeast Asia. Chinese government has presented the policy of "The vision and action of accelerating the construction of silk road economic belt and maritime silk road in the $21^{\text {st }}$ century based on the innovation cooperation mode" in March of 2015 for guiding the path of this strategy.

Acknowledgment. Funds for this research was provided by the Special Program For Key Program for International S\&T Cooperation Projects(2012DFA60830), the National Planning of Social Science, Funding Project(11\&ZD168) and Supported by Program for Changjiang Scholars and Innovative Research Team in University (IRT13062)

Author. Sisavath THIRAVONG (1959-), Male, Vientiane, Ph.D, Mainly engaged in strategic management research. QIN Jing(1984-), Male, Suqian, PH.D, Engineer, Mainly engaged in Geotechnical Engineering research.

Corresponding Author. Jingrong Xu(1989-),Male, Nantong, Ph.D, Mainly engaged in Management Science and Engineering research. 
Laos is a landlocked country with advantages of location in northern Indo-China Peninsula, whose south is Cambodia, north is China, northwest is Myanmar, and southwest is Thailand. The "great Mekong sub-regional economic cooperation" (GMS) has an important strategic position within the economic cooperation between China and ASEAN. Compared with other countries in the "neighborhood" all the way along the route of "One Belt One Road", Laos is considered as an all-weather strategic partner of China in Indo-China Peninsula because of its political and social stability, economic growth speed, high degree of political trust and highly complementary economic cooperation with China. In addition, Laos is in poverty but not in infertility, which is rich in natural resources, whose economy gained a momentum of rapid growth after joining the WTO in 2012. The 9th National Congress of Laos Revolutionary Party put forward the national development strategy to "get rid of the less developed countries state" in 2020 based on Chinese reform and opening up and development experience to Laos by "closed country" into an "open country". That also advocates accepting and agreeing the ideas and values of "regional development", all of these strategies become the solid material foundation and strategic environment for the economic cooperation and implement cross-border collaboration between Laos and China.

Laos Savan Water Economic Zone, located in south central of Laos, mainly including Khammouane and Savannakhet, is next to Vietnam in the east and Thailand in the west. Khammouane is located in the middle part (near southern part) of Loans, Thailand is located in its west, Vietnam is located in its east, Bolikhamsai is located in its north and Savannakhet is located in its south, Savannakhet is in its south, Savannakhet has 9 counties, an area of $16,315 \mathrm{~km}^{2}$, population of 298,000 and provincial capital is Thakhek; Savannakhet is located in southern part of Laos, facing Thailand in the west across Mekong River, next to Vietnam in the east, has 15 counties, it enjoys an area of $21,774 \mathrm{~km}^{2}$, the population of about 954,000 , the capital is Kaysone Phomvihane. National territorial areas of two provinces account for $16 \%$ of that of Laos and the population accounts for $20 \%$. Khammouane and Savannakhet enjoy the good geographical location with No. 9, No. 12 and No. 13 national highways passing through them, and are important geographic centers and main agricultural areas of production.

Savan-Seno Special Economic Zone is built by Laos and China together, involved two main subjects. There is a big gap between the two main economic dimensions, compared to China, Laos has lower technical level, but is richer in resources, How to coordinate the relationship between the two subjects? Therefore, this paper studies the symbiotic theory of ecology and from a new perspective to studies the relationship between the two subjects.

\section{Literature review}

Cross-border economic cooperation is refers to the adjacent two countries on different levels of resource, technology, market and capital. The elements of the two countries can make use of their complementary advantages of production factors of forms of cooperation that enjoy preferential policies such as export processing zone, bonded zone, free trade area to promote economic development between the two countries. For cross-border research of regional economic cooperation, the earliest dates back to international trade theory of classical economics. Classical trade theory achieves the objective of the international economic cooperation based on the international movement 
of goods. Proposed the theory of "boundary effect" of the early economic geography, think that the existence of national boundaries will affect the free flow of goods, which influence the development of trade, inhibit the development of national economy, such as Losch (1944), Ciersch (1949195) and Heigl $(1978)^{[1]}$. Brocker (1984) using a district-level trade gravity model, empirically the effect of the European Community boundaries, think the border trade barriers produced obvious effect ${ }^{[2]}$. Domestic scholar Li Tianzi (2015) by using gravity model, make empirical analysis of the boundary effect of the cross-border economic cooperation by using the 199 Chinese border city of data. He believe China's cross-border economic cooperation has higher boundary effect ${ }^{[3]}$. Yang Rong-hai, Li yabo (2014) in Yunnan region of Vietnam, Laos and Myanmar cross-border economic zone as the object, the empirical test the existence of border effect of economic cooperation zones between China and Vietnam, Laos and Myanmar, the boundary effect is shown by the mediation effect, while the intermediary effect is positive, can effectively promote the level of open of bambina in southwest China ${ }^{[4]}$.

Regional economic theory holds that due to the differencesin natural resources, social cultural and the level in factors of production,different economic regions has the characteristics of imbalance. Cross-border economic cooperation is emerging a new pattern of regional economic cooperationin recent years,Zhang Lijun (2014)is analyzed the inevitability of China's cross-border economic cooperation and the objective requirements on the basis of the theory of regional economic integration, and proposed the measures of China's cross-border economic cooperation ${ }^{[5]}$. From the perspective of regional economics, Jiang Yongming (2009) holds that the theoretical basis of international economic cooperation included regional spatial interaction theory, regional spatial structure theory and transnational regional governance theory, he focused on the European Union, North America and east Asia international economic cooperation zoneand analyzedthat the cooperation mode and path selection, system is important to attacked in the international regional economic cooperation ${ }^{[6]}$. From the perspective of regional economic theory, three scholars who Fure J S (1997) ${ }^{[7]}$, Blatter J (2000) ${ }^{[8]}$, Hanson G H (2001) ${ }^{[9]}$,analyzed the influence factors of cross-border economic cooperation and cross-border economic cooperation were the major influencing factors of political factors, institutional factors and transportation cost. Tang Zhongjian、Zhang Bing、Chen Ying(2002) have viewed the east Asian region as the research object and putted forward the three modes of cross-border economic cooperation: channel models, trade port mode and development zone ${ }^{[10]}$.

"Symbiosis Theory" thinks that symbiosis is a common phenomenon between nature and human society while the nature of symbiotic is consultation and cooperation and mutualism is the inevitable trend of human society and the natural symbiosis. Mutually beneficial relationship is the strategic basis for cross-border economic cooperation, as well as the premise of countries`cooperation. Zhiming Leng and Heping ZHANG(2007) regarded the core issues of regional economic cooperation as a starting point and found that regional economic problems and symbiosis theory has a strong consistency and applicability on the objectives and mechanisms of regional economic cooperation ${ }^{[11]}$.Baojie YI and Jieyan ZHANG(2015) analyzed the applicability of symbiosis theory on "One Belt and one Road" cooperation in Northeast Asia, and put forward the idea that the establishment of symbiosis mechanism and cooperation model innovation of "One Belt and one Road" in Northeast Asia should be focused on deepening the system platform, enhancing interaction and cooperation in a comprehensive upgrade 
regional cooperation in the Tumen River development ${ }^{[12]}$.

Throughout the literature and we can find that scholars focus more on regional economic cooperation with the research literature symbiosis theory but rarely the study of cross-border regional economic cooperation. Cross-border economic cooperation involves a number of economic entities and "Laos - China" cross-border economic cooperation faces the problem that what the mode of cooperation between the various economic agents is. After the analysis of the literature we can find that regional economic cooperation can be used on symbiosis theory. Therefore, this article intends to use the symbiotic theory to research "Lao - Chinese" cross-border economic cooperation, focusing on the Laos Haven water economic district as the specific objects.

\section{The generation of "Laos - China" regional economic cooperation symbiotic system}

(1) At least one group of quality parameters of the cross-border collaboration concert is compatible.

(2) Cross-border collaboration subject shall at least form one symbiosis interface, while the subject factors for the collaboration can act freely in the symbiosis interface.

(3) Subject factors of cross-border collaboration parties have flowability.

(4) Symbiosis units need energy for interaction through symbiosis interface.

(5) Information richness between entities for cross-border collaboration not less than a certain threshold.

With the analysis of the above 5 conditions, for the "Laos - China" Symbiosis system, the key to generate symbiotic system is that each participant economic agents must be compatible with each other, the degree of homogeneity should be higher than the critical value, cross-border economic cooperation body (the main parameter) information on the other side of the master degree (information abundance), their own benefits and win-win benefits (symbiotic energy) by the cooperation. Since the establishment of diplomatic relations between Laos and China, the two countries have established a very strong economic ties after decades of development. The changes of industrial structure and business structure of one country will result in the related economic benefits changes in the other country. Regarding to the Laos Haven water economic district, Lao Chamber of Commerce and the China Power Construction Group Co., Ltd. Kunming Survey and Design Institute has already launched a number of cooperation projects, which shows that Laos and China can express the related quality parameters each other and the economic symbiotic relationship has been established between Laos and China. Laos and China are bounded and have been developing the economic cooperation for a long history. During such a Laos - China cross-border regional economic cooperation system, the subject to establish "One Belt and one Road" is to choose a practical and efficient cooperation way to seek common development, enabling cooperation to get better economic utility.

\section{4."Lao - China" symbiotic system optimization of the regional economic cooperation}

Incentive efficiency is the important condition of symbiotic system optimization; the ideal incentive efficiency can make the symbiosis body common symmetric mutual symbiotic evolution towards integration, to attain the ideal incentive efficiency, symbiotic system works the same 
production of energy in different symbiotic unit ${ }^{[13]}[14]$, Is $E_{s i} / E_{e i}=E_{s j} / E_{e j}$, Laos - China's "economic cooperation system is a two-dimensional symbiotic system, in certain cases of the symbiotic interface. When the main quality parameters is fixed of $Z_{i}$ and $Z_{j}$. Symbiosis energy is respect of $E_{s i}=S_{i}\left(\rho_{i}, \rho_{j}, \eta_{i}, \eta_{j}\right), E_{s j}=s_{j}\left(\rho_{j}, \rho_{i}, \eta_{j}, \eta_{i}\right)$. The loss of symbiosis energy is respect of $E_{e i}=C_{i}\left(\rho_{i}, \rho_{j}, \eta_{i}, \eta_{j}\right), E_{e j}=C_{j}\left(\rho_{j}, \rho_{i}, \eta_{j}, \eta_{i}\right)$.The net energy of symbiotic system is $\Delta E=\left(E_{s i}+E_{s j}\right)-\left(E_{e i}+E_{e j}\right)$.

The optimization of the conditions in Laos - "China economic cooperation system is:

$$
\begin{aligned}
& \operatorname{Max} \Delta E=\left(E_{s i}+E_{s j}\right)-\left(E_{e i}+E_{e j}\right) \\
& \text { s.t. } E_{s i} / E_{e i}=E_{s j} / E_{e j}
\end{aligned}
$$

Using the Lagrange multiplier method to calculate the optimized conditions:

$$
\begin{aligned}
& \partial E_{s i} / \partial \rho_{i}=\partial E_{e i} / \partial \rho_{i} \\
& \partial E_{s j} / \partial \rho_{j}=\partial E_{e j} / \partial \rho_{j} \\
& \partial E_{s i} / \partial \eta_{i}=\partial E_{e i} / \partial \eta_{i} \\
& \partial E_{s j} / \partial \eta_{j}=\partial E_{e j} / \partial \eta_{j} \\
& E_{s i} / E_{e i}=E_{s j} / E_{e j}
\end{aligned}
$$

(1) (2) is symbiosis density equilibrium conditions.(3) (4) is the symbiotic dimension equilibrium conditions. When a symbiotic system of symbiotic energy with the depletion of the symbiotic energy satisfy this five equations of (1) (2) (3) (4) (5)at the same time. There are symbiotic system presents the structural matching, symbiotic system maximize the interests of symbiosis on any subjects to achieve the goal of convolution. Based on the above analysis, for "Laos - China" symbiotic system optimization, regional economic cooperation is the optimization of its economic main body density and symbiosis symbiotic dimension, but the most important point is structural optimization, specific to shawan water in terms of economic zone, economic zone is wading industries and gigantic symbiotic system density, wading enterprises economic zone of China. Cooperation deeply continued and symbiotic system dimensions are more and more widely.

\section{5.generation of the symbiotic energy of the "Lao China"regional economic cooperation}

One of the most important essential characteristics is produced new energy symbiotic process, called symbiosis energy. If the symbiotic system $\mathrm{S}$ has a quality parameter $Z_{S}$, and there are $m(m \geq 2)$ symbiotic units, then:

$$
Z_{S}=f\left(Z_{1}, Z_{2} \mathrm{~L} Z_{i} \mathrm{~L} Z_{m}\right)
$$

The total factor of system $\delta_{s}$ is:

$$
\delta_{s}=\frac{1}{\lambda} \sum_{i=1}^{m} \delta_{s i}
$$


$\lambda$ is the characteristic coefficient of symbiotic interface, and $\delta_{s i}$ is one of the symbiotic system.

Symbiosis energy $\left(E_{S}\right)$ is the concrete embodiment of the existence and value added ability of the symbiotic system. The principle of symbiosis energy production shows that the system which does not produce symbiotic energy can not be added and developed. Under normal circumstances, the generation of symbiotic energy is mainly influenced by the total factor, when $\delta_{s}>0$, will produce symbiotic energy ${ }^{[14]}$. But at the same time, the symbiotic energy is related to the density and the symbiotic dimension, then $E_{S}=f\left(\delta_{s}, \rho_{s}, \eta_{s}\right)$ or $\delta_{s}^{m}=\sum_{i=1}^{m} \delta_{s i} \cdot \rho_{s}$ is the symbiotic density, and $\eta_{s}$ is the symbiotic dimension.For the "Lao-China" economic cooperation, such a two-dimensional symbiotic system, the symbiotic system $E_{s}$ can be expressed as followed:

$$
E_{s}=f_{s}\left(Z_{a}^{m}, Z_{b}^{m}, \theta_{a b}, \lambda, \rho_{s a}, \rho_{s b}, \eta_{s a}, \eta_{s b}, F, \delta_{s}\right)
$$

$F$ is the symbiotic environment of symbiotic system.

Therefore, "Laos - China" Economic Cooperation symbiosis energy generation is to be maximize, not only to conforms to the symbiotic system optimization conditions, also with main quality parameters of governance, symbiotic interface, symbiosis of the quality of the environment related. Put it differently: the quality of main quality parameters, symbiotic density, symbiotic dimension, the symbiotic interface and symbiotic environment are jointly decided to symbiosis energy size. How to improve economic cooperation, the "Laos China" symbiosis energy, specific to the Savan-Seno Special Economic Zone, its intrinsic requirement is to improve the cross-border economic subject characteristics, so as to achieved the structural matching; improved the cross-border economic entities symbiotic density and dimension; the expansion of the cross-border economic entities symbiotic interface; cultivated and selected the symbiotic environment conducive to cooperation.

\section{Conclusions}

This article explores the symbiotic relationship between Laos and China economies under "One Belt and one Road" Project. Through analysis, we find the typical symbiotic relationship between Laos and China economic cooperation. To establish "One Belt and one Road" together is internal demand of the two countries` economic development strategy as well as the external requirement of regional economic cooperation.

The establishment of Laos Haven water economic district is the specific applications in Laos and China cross-border economic cooperation, whose symbiotic system has symbiotic units consisting of 
"three levels, six co-factor": government level, social organization level and the level of industry, university, research and financial; education, science and technology, entrepreneurship, finance, industry, and culture. The two governments should strengthen communication and collaboration: to optimize the allocation of the six elements, and promote the flow of the six elements. So that the two governments can work and combine with each other. The two governments should strengthen the regulatory role: to guarantee the enterprises settled in the region in line with the requirements of the economic area, to draft more policies and measures, and to promote bilateral business cooperation, in order to improve the density of the symbiosis density and dimensions of symbiotic systems of water economic area and to optimize the industrial structure in the area. In this way, provide support for the energy cogeneration system and promote the continuous optimization of the symbiotic system 


\section{Reference}

[1] FENG Ge-qun,DING Si-bao. RetrosPect and ProsPect of the Cross-Border CooPeration Study[J].World Regional Studies,2005,14(1):53-60

[2] Bröcker J. How do international trade barriers affect interregional trade[J]. Regional and industrial development theories, models and empirical evidence, 1984: 219-239.

[3] LI Tian-zi. Boundary Effect of Chinese Cross-Border Economic Cooperation[J].Economic Geography,2015,10:5-12.

[4] Yang Ronghai,Li Yabo. Will Border Effect Restrict the Construction of China's Cross-Border Cooperation Zone?:An Analysis Based on the Date of China and Vietnam,Laos and Burma[J]. International Economics and Trade Research,2014,v.30; 20703:73-84.

[5] ZHANG Lijun,ZHENG Yan.Achievements,Problems and Countermeasures of Border Trade of Yunnan province[J].Journal of Minzu University of China(Philosophy and Social Sciences Edition) ,2014,v.41;No.21302:43-51.

[6] Jiang Yongming.CROSS-National Regional Economic Cooperation and Development[D]. Jilin University,2009.

[7] Fure J S. The German-Polish Border Region: A Case of Regional Integration?[M]. ARENA, 1997.19

[8] Blatter J. Emerging cross-border regions as a step towards sustainable development[J]. International Journal of Economic Development, 2000, 2(3): 402-439.

[9] Hanson G H. US-Mexico integration and regional economies: evidence from border-city pairs[J]. Journal of Urban Economics, 2001, 50(2): 259-287.

[10] TANG Jian-zhong, ZHANG Bing, CHEN Ying. The Boundary Effect and Cross-Border Subregional Economic Cooperation-A Case Study of East Asia[J].Human Geography,2002,01:8-12.

[11] LENG Zhi-ming,ZHANG He-ping. The Cooperating Mechanism of Regional Economic Development BasedSymbiosis Theory[J]. Economic Review,2007,No.25707:32-33.

[12]YI Baozhong,ZHANG Jieyan. Study on "One Belt One Road" Cooperation Symbiotic System of North-East Asia[J].Northeast Aisa Forum ,2015,v.24;No.11903:65-74+127-128.

[13] Chen Sihui.PPRD Economic Cooperation in the perspective of the Symbiotic Theory[J]. Journal of Yunnan Nationallities University(Social Sciences) ,2012,02:115-123.

[14] Ling Dan. The Study on Supply Chain Alliance based on the Symbiosis Theory[D]. Jilin University,2006 